\title{
CORRECTION
}

View Article Online

View Journal I View Issue

Check for updates

Cite this: J. Mater. Chem. A, 2020, 8 , 16698

DOI: 10.1039/d0ta90175j

rsc.li/materials-a

\section{Correction: Facile synthesis of titanium nitride nanowires on carbon fabric for flexible and high- rate lithium ion batteries}

\author{
Muhammad-Sadeeq Balogun, ${ }^{a}$ Minghao Yu, ${ }^{a}$ Cheng Li, ${ }^{a}$ Teng Zhai, ${ }^{a}$ Yi Liu, $^{\text {ab }}$ \\ Xihong Lu*a and Yexiang Tong ${ }^{\star a}$
}

Correction for 'Facile synthesis of titanium nitride nanowires on carbon fabric for flexible and high-rate lithium ion batteries' by Muhammad-Sadeeq Balogun et al., J. Mater. Chem. A, 2014, 2, 10825-10829, DOI: 10.1039/C4TA00987H.

The authors regret an error in Fig. S3a of the published article. Two identical sets of XPS data (which were data for sample TiN-900) were accidentally plotted and labelled as data for samples TiN-800 and TiN-900. A corrected version of Fig. S3a is provided here.

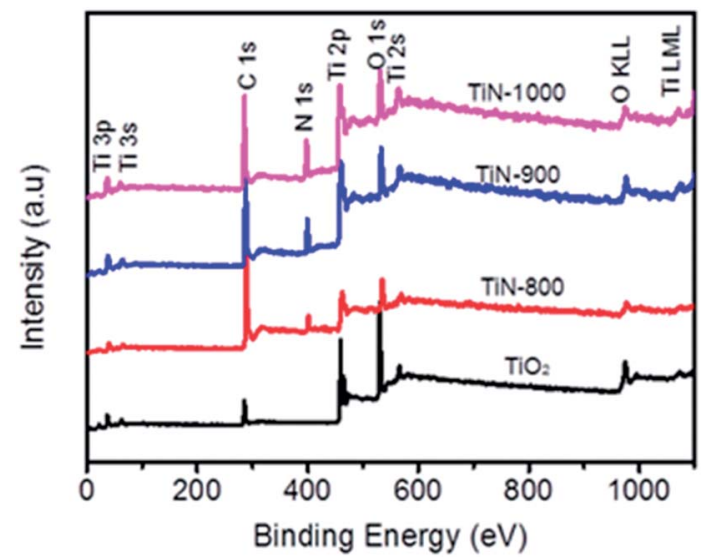

Fig. S3(a) XPS survey spectra of $\mathrm{TiO}_{2}$ and TiN nanowires.

The Royal Society of Chemistry apologises for these errors and any consequent inconvenience to authors and readers. 